\title{
Design of Pyrene-Fatty Acid Conjugates for Real-Time Monitoring of Drug Delivery and Controllability of Drug Release
}

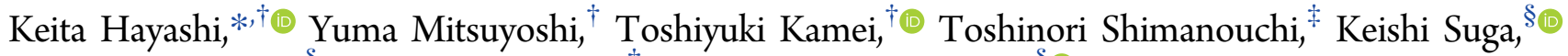
Yukihiro Okamoto, ${ }^{\S}$ Hidemi Nakamura, ${ }^{\dagger}$ and Hiroshi Umakoshi*, ${ }^{\S} \odot$

${ }^{\dagger}$ Department of Chemical Engineering, National Institute of Technology, Nara College, 22 Yata-cho, Yamatokoriyama, Nara 639-1080, Japan

${ }^{*}$ Department of Material and Energy Science, Graduate School of Environmental Science, Okayama University, 3-1-1 Tsushima-Naka, Okayama 700-8530, Japan

${ }^{\S}$ Division of Chemical Engineering, Graduate School of Engineering Science, Osaka University, 1-3 Machikaneyama-cho, Toyonaka, Osaka 560-8531, Japan

\section{Supporting Information}

ABSTRACT: Fluorescence probes are usually employed to analyze pharmacokinetics of drug carriers; however, this method using usual probes is not suitable to monitor drug carriers in detail because fluorescence spectra do not change by the disruption of drug carriers. In this study, pyrene-fatty acid conjugates were investigated as probes to monitor the state of drug carriers in real time. 1-Pyrenemethanol was conjugated with fatty acids, such as lauric acid, stearic acid, and behenic acid, and the conjugates were stirred in ethanol, resulting in the formation of submicron particles; these particles exhibited excimer emission. When J774.1 and Colon 26 cells were treated with these particles, the associated fluorescence spectra

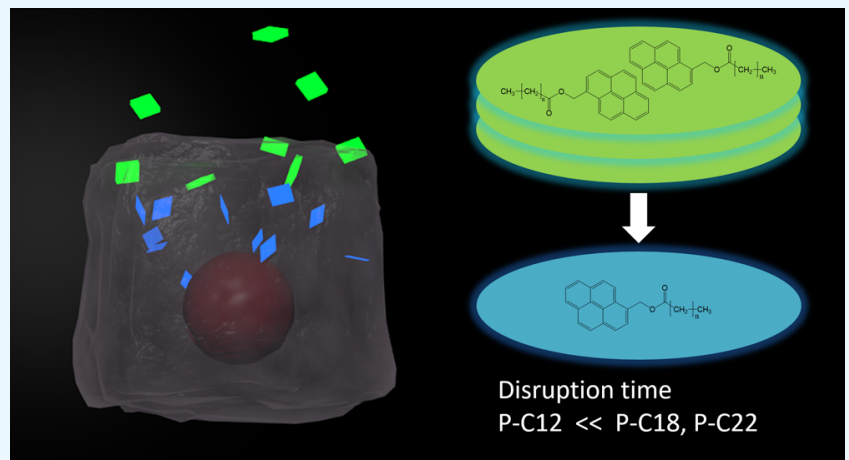
shifted from excimer emission to monomer emission. Moreover, the degree of change was controlled by the type of fatty acid. These results support the design of drug carriers that can be used to monitor pharmacokinetics in real time and to control the disruption time.

\section{INTRODUCTION}

Nowadays, fluorescent materials are being used in many devices, including lasers, ${ }^{1}$ organic electroluminescence displays, ${ }^{2}$ biosensors, ${ }^{3,4}$ and bioimaging probes. ${ }^{5}$ In this context, a few small organic molecules and fluorescent proteins are being studied specifically for application as fluorescence probes in bioscience. An advantage of small organic molecules is their design flexibility. Small organic molecules can easily be modified by organic chemical reactions to enable suitable exciting and emission wavelengths. ${ }^{6-9}$ These molecules can also be conjugated with other substances, such as proteins, ${ }^{10}$ peptides, ${ }^{11-13}$ DNA, ${ }^{14,15}$ lipids, ${ }^{16-18}$ and silica particles, ${ }^{19}$ which proves their applicability in bioscience.

Pyrene and pyrene derivatives are organic molecules typically used as fluorescence probes. A highly concentrated pyrene solution $^{20}$ or pyrene in the solid state ${ }^{21}$ shows an excimer emission at $\sim 475 \mathrm{~nm}$ because of $\pi-\pi$ stacking. ${ }^{22}$ This phenomenon can be applied to monitor inter and intramolecular interactions. For example, the interaction of a single strand of DNA was monitored using interstrand stacked pyrenes. $^{23}$ The formation of double-strand DNA was revealed by the change in the fluorescence spectrum of pyrene from monomer emission to excimer emission. Further, the interaction between dipeptidyl ureas was investigated based on the conjugation of dipeptidyl urea and pyrene. ${ }^{24}$ However, excimer emission is dependent not only on the molecules but also on molecule aggregation. Pyrene and pyrene derivatives are also used as probes to monitor the formation of micellar aggregates $^{25,26}$ and gel matrices. ${ }^{27}$ Intriguingly, pyrene derivatives were applied to monitor ion species and their concentration. $^{28}$ Roy et al. developed phospholipid vesicles (liposomes) containing lipid molecules with both pyrene (in the tail) and metal ion chelators (in the head group); the liposomes exhibited pyrene excimer fluorescence in the presence of a copper ion. Ion monitoring was accomplished not only by the change to excimer emission but also by the change to monomer emission. ${ }^{29}$ Two pyrene moieties linked with $\mathrm{O}-\mathrm{Si}-\mathrm{Si}-\mathrm{O}-$ or $\mathrm{O}-\mathrm{Si}-\mathrm{O}-$ chains show excimer emission in a tetrahydrofuran (THF) $/ \mathrm{H}_{2} \mathrm{O}$ (v/v, 50/50) solution. This molecule was incubated with a fluorine ion, resulting in a change from excimer emission to monomer emission because of bond cleavage.

Received: December 25, 2017

Accepted: March 15, 2018

Published: March 28, 2018 
$\pi-\pi$ stacking is also expected to facilitate pharmacokinetic analysis. In general, to analyze the pharmacokinetics of drug carriers, fluorescence probes containing drug carriers are used. However, this method cannot track the drug carrier itself but tracks only the fluorescence probes. Therefore, it is difficult to detect "when" and "where" a drug capsule is disrupted and the encapsulated drug is released. To control the pharmacological effect of drug carriers, it is necessary to control the retention time (such as the development of PEGylated liposomes to achieve long circulation times in the blood $\left.{ }^{30,31}\right)$. In recent years, the focus of research shifted from drug delivery at the disease site to organelle-specific targeting. ${ }^{32-34}$ Thus, it is important to develop fluorescence probes to detect when and where drug carriers are disrupted and drugs are released not only at the organ level but also at the organelle level.

In this study, particles composed of pyrene-fatty acid conjugates were investigated as trackable drug carriers or excipients. Fatty acids are typical biomolecules found in cell membranes and are considered biocompatible. It is widely recognized that it is important to design biomaterials depending on the purpose..$^{35-38}$ In this context, it is easy to control the physicochemical properties of biomaterials composed of fatty acids by tailoring the length of the fatty acid. Herein, lauric acid, stearic acid, and behenic acid were conjugated with 1-pyrenemethanol. Solid-state pyrene-fatty acid conjugates were characterized in terms of their physicochemical properties and fluorescence spectra. Later, suspended pyrene-fatty acid conjugates in ethanol (EtOH) were added to murine cells. The conjugates were immediately taken up by the cells and subsequently disrupted. Finally, the relationship between the time to disruption and acyl chain lengths of the fatty acids is discussed.

\section{RESULTS AND DISCUSSION}

2.1. Physicochemical Properties of Pyrene-Fatty Acid Conjugates. Pyrene-fatty acid conjugates synthesized with lauric acid, stearic acid, and behenic acid are designated as $\mathrm{P}-$ $\mathrm{C} 12, \mathrm{P}-\mathrm{C} 18$, and $\mathrm{P}-\mathrm{C} 22$, respectively, and their chemical structures are shown in Figure 1a. They were further characterized by fluorescence microscopy, and the results are shown in Figure 1b. The conjugates were found to be

(a)

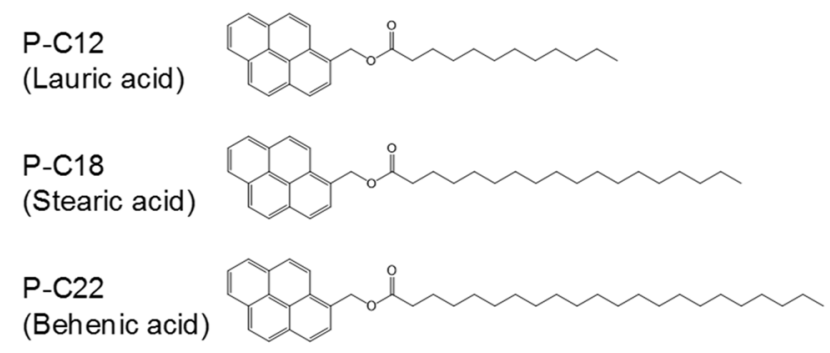

(b)

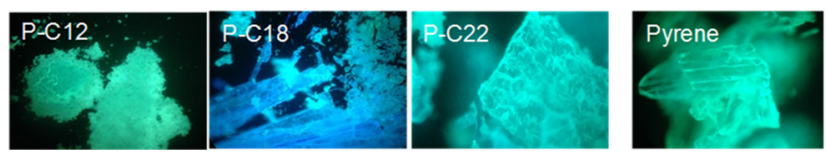

Figure 1. (a) Chemical structure of pyrene-fatty acid conjugates (lauric acid (C12), stearic acid (C18), and behenic acid (C22)). (b) Fluorescence microscopy images of the pyrene-modified fatty acids. crystalline in nature; Figure 2a shows their powder X-ray diffraction (PXRD) patterns. Sharp peaks could be clearly observed, and the recorded patterns were different from those of pyrene. This result suggests that these pyrene-fatty acid conjugates exhibit different crystalline structures. According to differential scanning calorimetry (DSC) analysis, some of the fatty acid molecules show not only a melting point but also a glass transition (Figure S1). ${ }^{39}$ Figure $2 \mathrm{~b}$ shows the DSC curves of the synthesized pyrene-fatty acid conjugates. Although no glass transition could be observed, sharp peaks ascribed to melting were apparent; melting peaks corresponding to $\mathrm{P}-$ $\mathrm{C} 12, \mathrm{P}-\mathrm{C} 16$, and $\mathrm{P}-\mathrm{C} 22$ were found at $67.30,82.02$, and $89.50{ }^{\circ} \mathrm{C}$, respectively. Thus, these pyrene-fatty acid conjugates remain in the crystalline form at $37{ }^{\circ} \mathrm{C}$ (normal body temperature). Moreover, Raman spectroscopy also supported the formation of stable crystalline structures (Figure $2 c)$. The peaks at 1074 and $1130 \mathrm{~cm}^{-1}$ are assigned to gauche $\mathrm{C}-\mathrm{C}$ stretch $\left(v(\mathrm{C}-\mathrm{C})_{\mathrm{G}}\right)$ and trans $\mathrm{C}-\mathrm{C}$ stretch $\left(v(\mathrm{C}-\mathrm{C})_{\mathrm{T}}\right)$, respectively, and the ratio of these peak intensities indicates the ordering of pyrene-fatty acid conjugates. ${ }^{40}$ Peaks at $1130 \mathrm{~cm}^{-1}$ could be clearly observed in the case of $\mathrm{P}-\mathrm{C} 18$ and $\mathrm{P}-\mathrm{C} 22$. This result indicates that the hydrocarbon chains of $\mathrm{P}-\mathrm{C} 18$ and $\mathrm{P}-\mathrm{C} 22$ are crystalline in nature. The peak intensities at 1074 and $1130 \mathrm{~cm}^{-1}$ were very weak in the case of $\mathrm{P}-\mathrm{C} 12$. This might be ascribed to the difficulty in detecting short acyl chains. Moreover, it has been reported that at wavenumbers smaller than $600 \mathrm{~cm}^{-1}, \mathrm{C}-\mathrm{C}-\mathrm{C}$ out-of-plane bending vibrations occur, whereas in the wavenumber range of $1250-1000 \mathrm{~cm}^{-1}, \mathrm{C}-\mathrm{H}$ in-plane bending and rocking occur. ${ }^{41}$ At the same time, in the wavenumber range of $1650-1300 \mathrm{~cm}^{-1}$, aromatic C-C stretching vibrations occur. ${ }^{41}$ These wavenumbers of peaks were not completely same, although these peaks were observed in all samples. This result suggests that the stacking states of the pyrene-fatty acid conjugates were different from each other.

2.2. Optical Properties of Pyrene-Fatty Acid Conjugates. To analyze the applicability of the synthesized pyrene-fatty acid conjugates, their optical properties, especially excimer emission properties, were investigated. Figure $3 \mathrm{a}, \mathrm{b}$ shows the absorption and fluorescence spectra of pyrene, $\mathrm{P}-$ $\mathrm{C} 12, \mathrm{P}-\mathrm{C} 18$, and $\mathrm{P}-\mathrm{C} 22$ solubilized in hexane, respectively. In solution, the absorbance and fluorescence spectra of the pyrene-fatty acid conjugates were similar to each other but different from those of pyrene. The absorbance spectra of pyrene-fatty acid conjugates slightly red-shifted to longer wavelengths $(300-350 \mathrm{~nm})$. At $0.01 \mathrm{mM}$ pyrene concentration, the peaks of monomer emission were obviously different. The difference was significant in the fluorescence spectra in the wavelength range of $350-425 \mathrm{~nm}$ (inset of Figure $3 b$ ). This may be caused by the ester bond between pyrene and fatty acids. However, at high concentrations (2.5 $\mathrm{mM})$, the pyrene-fatty acid conjugates exhibited excimer emission peaks (Figure S2). Thus, the optical function of pyrene, that is, monomer/excimer fluorescence transition depending on the relative distance between fluorophores, was maintained in the solution form after conjugation with fatty acid molecules.

The absorption and fluorescence spectra of pyrene, $\mathrm{P}-\mathrm{C} 12$, $\mathrm{P}-\mathrm{C} 18$, and $\mathrm{P}-\mathrm{C} 22$ in the solid state are shown in Figure $3 \mathrm{c}, \mathrm{d}$. It could be observed that the monomer emission of pyrenefatty acid conjugates was different compared to that of pyrene. It has been reported that the modification of functional groups with pyrene can influence the appearance of their fluorescence spectra. ${ }^{6,42}$ Further, the excimer emission spectra of pyrene and 
(a)

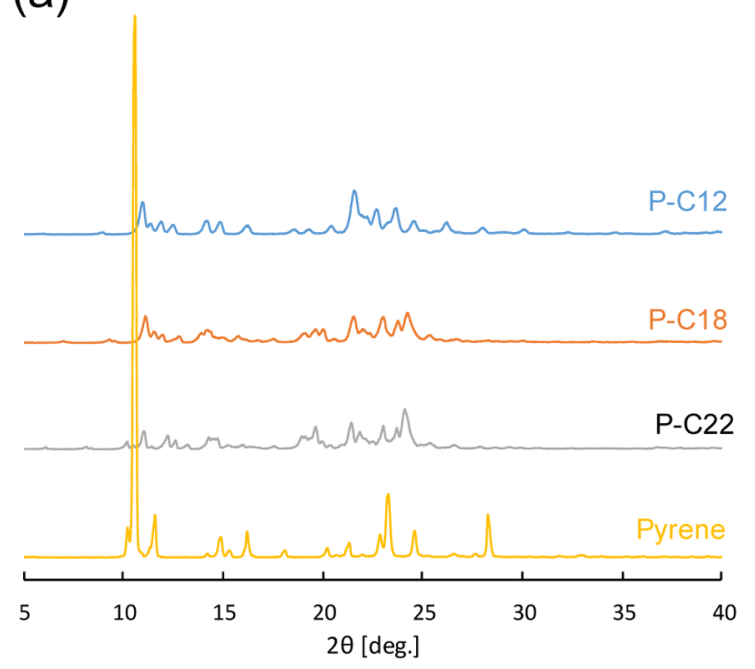

(b)

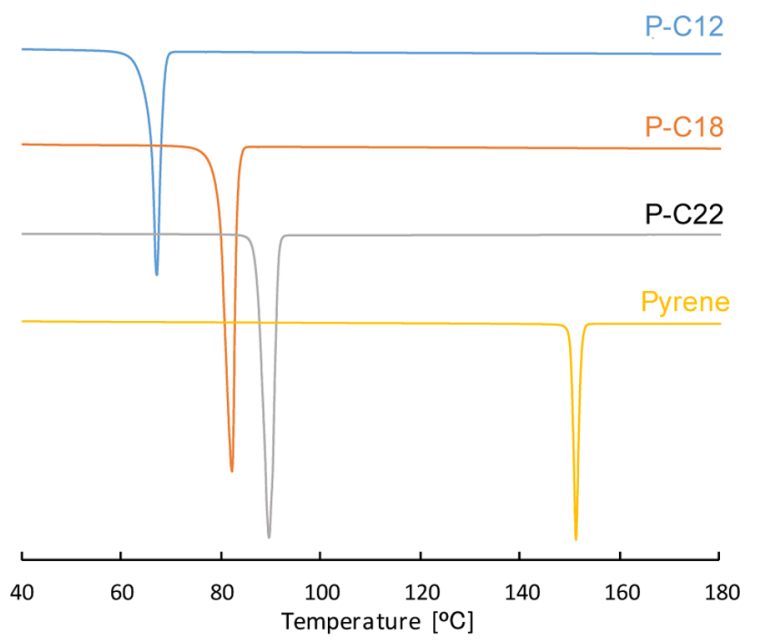

(c)

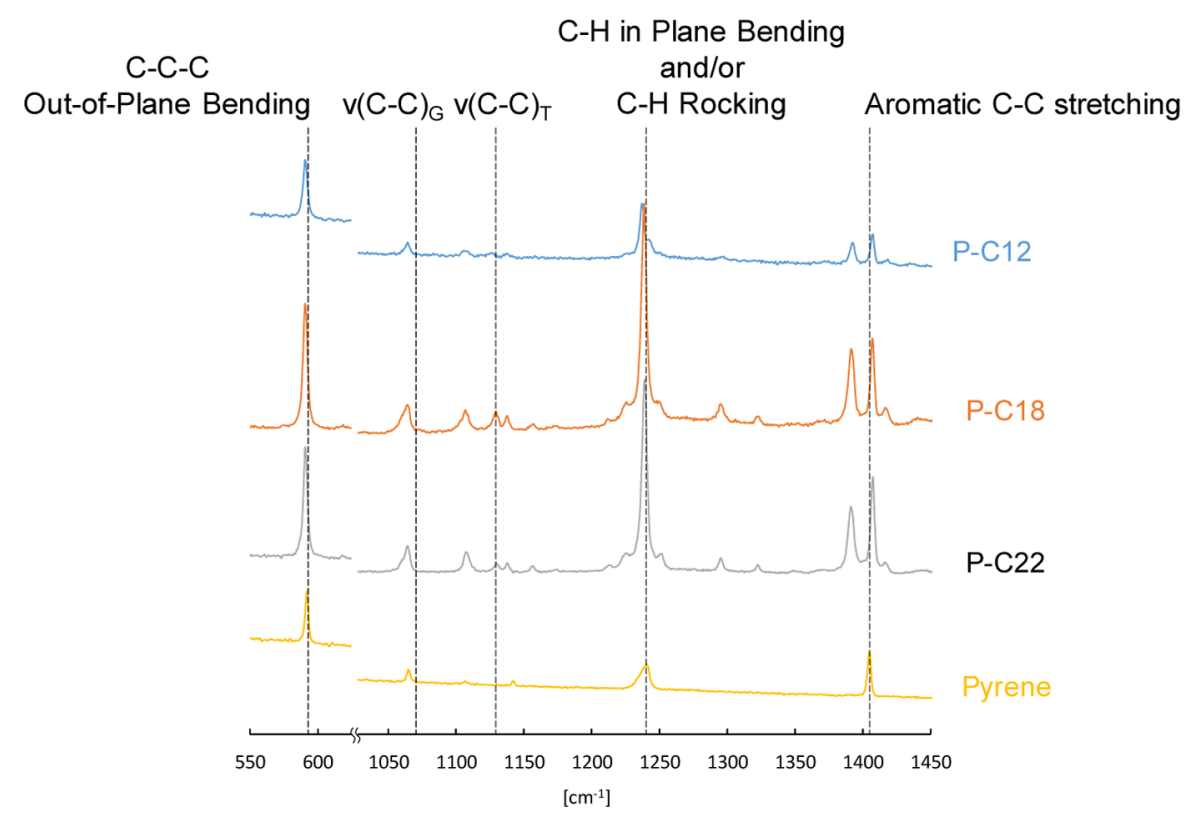

Figure 2. Characterization of pyrene-fatty acid conjugates-(a) PXRD, (b) DSC, and (c) Raman spectroscopy.

pyrene-fatty acid conjugates were also different from each other. It has been reported that absorbance peaks above 410 $\mathrm{nm}$ are related to excimer emission. ${ }^{43}$ The absorbance above $410 \mathrm{~nm}$ of pyrene was the highest within the pyrene derivatives tested in this study, and the excimer fluorescence intensity ratio of pyrene was certainly the highest. This observation suggests that the acyl chains of pyrene-fatty acid conjugates restricted the stacking of pyrene by steric hindrance. However, all pyrene-fatty acid conjugates showed excimer emission peaks similar to the spectra of pyrene-fatty acid conjugates solubilized in hexane at high concentrations. Therefore, these pyrene-fatty acid conjugates can potentially be applied as fluorescence probes in pharmacokinetic analysis.

2.3. Application of Pyrene-Fatty Acid Conjugates as Trackable Drug Carriers or Excipients. To treat cells with pyrene-fatty acid conjugates, the conjugates were initially suspended in EtOH. The spherical-equivalent diameters of the suspended particles and particle size distribution are shown in Table 1 and Figure S3, respectively. Particle size analysis is very important because it controls the endocytic pathway. ${ }^{44,45}$ The sphere-equivalent diameters of $\mathrm{P}-\mathrm{C} 12$ and $\mathrm{P}-\mathrm{C} 18$ particles were 94.0 and $122.8 \mathrm{~nm}$, respectively. On the other hand, the sphere-equivalent diameter of $\mathrm{P}-\mathrm{C} 22$ was $354.8 \mathrm{~nm}$, which is much larger than those of $\mathrm{P}-\mathrm{C} 12$ and $\mathrm{P}-\mathrm{C} 18$. When pyrenefatty acid conjugate suspensions were added to phosphatebuffered saline (PBS), fluorescence spectra were measured. The fluorescence spectra of the pyrene-fatty acid conjugate particles are not completely similar to those of pyrene-fatty acid conjugates in the solid state (Figures $3 \mathrm{~d}$ and 4 ). However, excimer emission peaks were observed. This result suggests that the suspended particles can be used as a fluorescence probe to analyze pharmacokinetic behaviors in detail.

To analyze the uptake pathway, the fluorescence intensities of the pyrene-fatty acid conjugates absorbed in cells were 


\section{Solution}

(a)

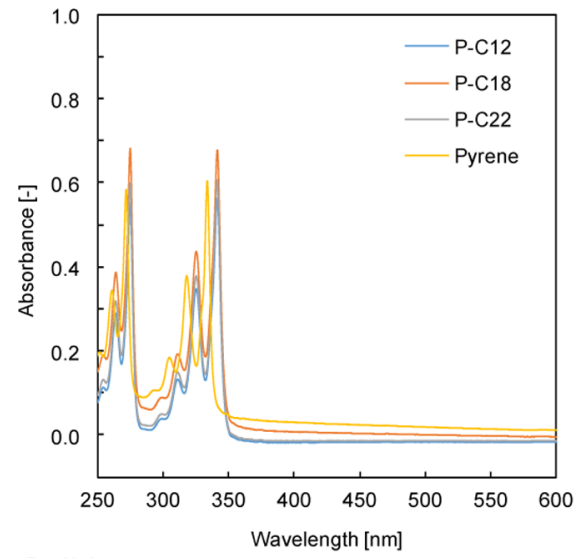

Solid

(c)

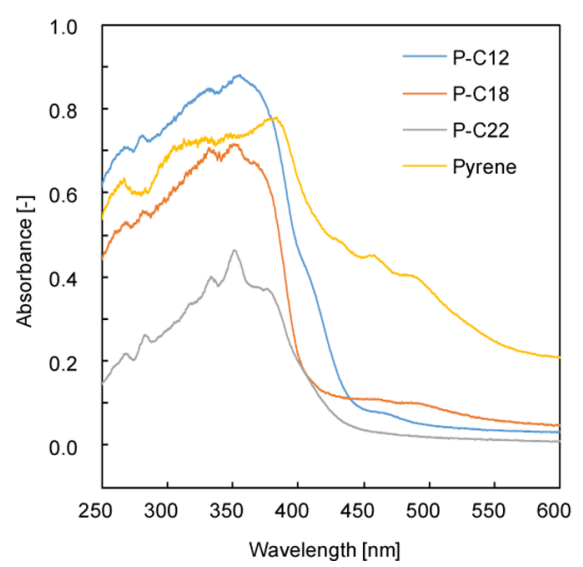

(b)

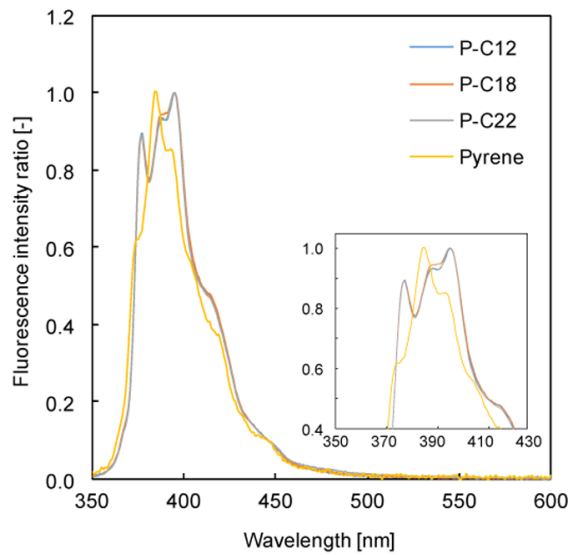

(d)

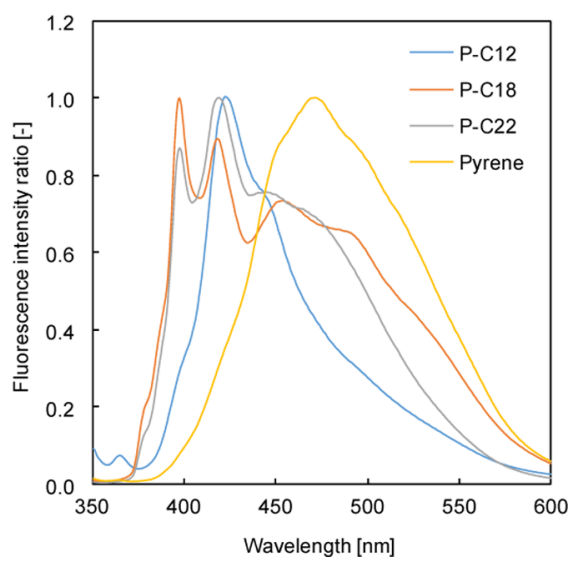

Figure 3. (a) Absorption and (b) fluorescence spectra of pyrene-fatty acid conjugates and pyrene in solution form (0.01 mM in hexane). (c) Absorption and (d) fluorescence spectra of pyrene-fatty acid conjugates and pyrene in the solid state.

Table 1. Sphere-Equivalent Diameters of Pyrene-Fatty Acid Conjugates

\begin{tabular}{|lc}
\hline sample & size $(\mathrm{nm})$ \\
\hline $\mathrm{P}-\mathrm{C} 12$ & 94 \\
$\mathrm{P}-\mathrm{C} 18$ & 123 \\
$\mathrm{P}-\mathrm{C} 22$ & 355 \\
\hline
\end{tabular}

measured after incubation at $4{ }^{\circ} \mathrm{C}$ or after treatment with an endocytosis inhibitor (Figure 5a). When J774.1 cells were incubated with pyrene-fatty acid conjugates at $4{ }^{\circ} \mathrm{C}$, the fluorescence intensities of the conjugates reduced. Similarly, the fluorescence intensities decreased when the conjugates were treated with endocytosis inhibitors, such as phenylarsine oxide (PAO), wortmannin, cytochalasin $\mathrm{B}$, cytochalasin $\mathrm{D}$, and ethyl isopropyl ether (EIPA). However, in the case of methyl- $\beta$ cyclodextrin $(\mathrm{M} \beta \mathrm{CD})$, there was no reduction in the fluorescence intensities of the pyrene-fatty acid conjugates. Therefore, the J774.1 cells took up pyrene-fatty acid conjugates by an endocytic pathway; the contribution of caveola-mediated endocytic pathways is little. No size-dependent differences could be observed in the endocytic pathways. On the other hand, when Colon 26 cells were treated with the pyrene-fatty acid conjugates, the reduction in their fluo-

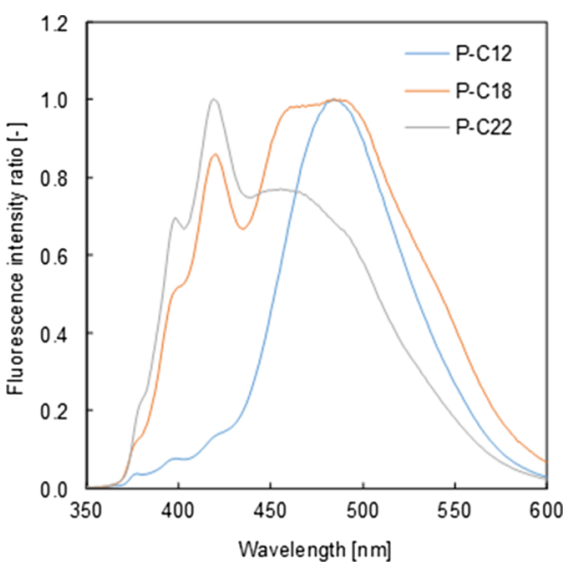

Figure 4. Fluorescence spectra of pyrene-fatty acid conjugate particles.

rescence intensities was not adequate enough to determine the endocytic pathway (Figure 5b). This suggests that the Colon 26 cells absorbed a part of the pyrene-fatty acid conjugates through the plasma membrane by diffusion. From this 
J774. 1 cell

(a)

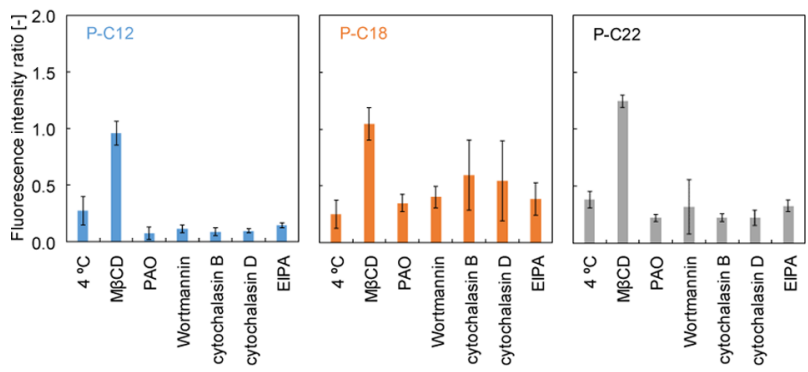

(c)

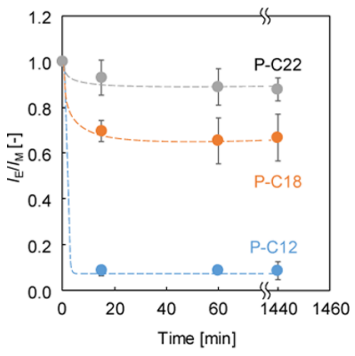

(e)

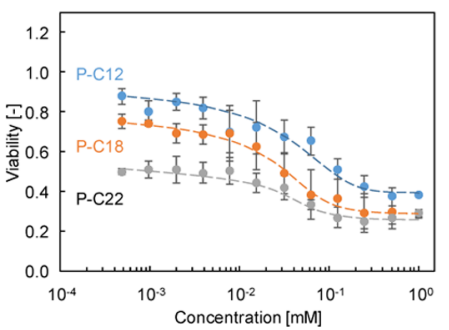

Colon 26 cell

(b)

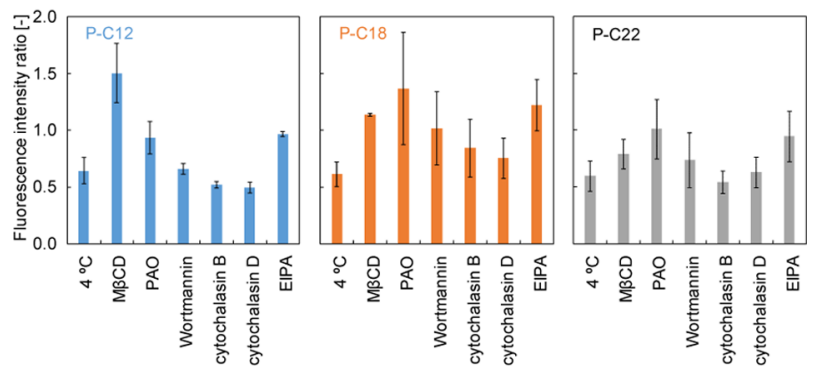

(d)

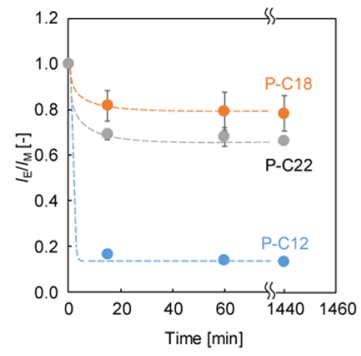

(f)

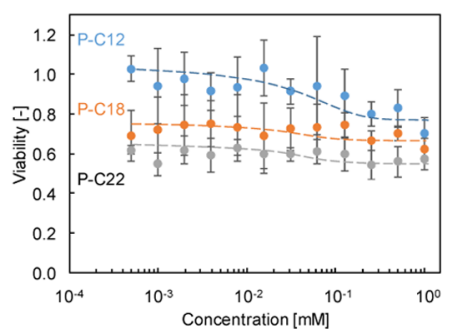

Figure 5. (a,b) Evaluation of the uptake mechanism (treatment with endocytosis inhibitors) of J774.1 cells and Colon 26 cells, respectively. (c,d) Measurement of the disruption time (ratio of excimer emission) and (e,f) cytotoxicity (MTT assay) of pyrene-fatty acid conjugates with respect to J774.1 cells and Colon 26 cells, respectively.

discussion, it is obvious that the uptake mechanism is dependent on the cell line.

Figure 5c,d shows the disruption times of the excimer fluorescence of pyrene-fatty acid conjugates used to treat J774.1 and Colon 26 cells, respectively. They were evaluated using the $I_{\mathrm{M}} / I_{\mathrm{E}}$ ratio. $I_{\mathrm{M}}$ and $I_{\mathrm{E}}$ show the maximum fluorescence intensity of monomer and excimer emission, respectively. When the J774.1 and Colon 26 cells were treated with $\mathrm{P}-\mathrm{C} 12$, the fluorescence spectra changed smoothly from an excimer emission mode to a monomer emission mode. After uptake by the cells, the excimer emission of $\mathrm{P}-\mathrm{C} 12$ decreased drastically, indicating that the assembly of pyrene-fatty acid conjugate particles was disrupted. Therefore, the particles of $\mathrm{P}-\mathrm{C} 12$ might be disrupted smoothly, independent of the cell line and uptake pathway. On the other hand, the changes in the fluorescence spectra of $\mathrm{P}-\mathrm{C} 18$ and $\mathrm{P}-\mathrm{C} 22$ were smaller than those in $\mathrm{P}-\mathrm{C} 12$. Therefore, it can be theorized that the particles of pyrene-fatty acid conjugates with longer acyl chains are not disrupted significantly.

The acyl chain lengths of pyrene-fatty acid conjugates also affected their cytotoxicity. Figure 5e,f illustrates the cytotoxicity of pyrene-fatty acid conjugates toward J774.1 and Colon 26 cells, respectively. The cytotoxicity of $\mathrm{P}-\mathrm{C} 12$ was less than that of $\mathrm{P}-\mathrm{C} 18$ and $\mathrm{P}-\mathrm{C} 22$. As described previously, the particles of
P-C12 were disrupted smoothly after uptake, independent of the cell line. Thus, it seems that pyrene-fatty acid conjugate particles were taken by the endocytic pathway, and $\mathrm{P}-\mathrm{C} 12$ was metabolized more smoothly compared to $\mathrm{P}-\mathrm{C} 18$ and $\mathrm{P}-\mathrm{C} 22$, resulting in a lower cytotoxicity (Figure 6).

\section{CONCLUSIONS}

The fluorescence spectra of pyrene changed from excimer emission to monomer emission because of the disruption of particles. On the basis of this property, pyrene-fatty acid conjugates can be used to analyze pharmacokinetics. Moreover, the particle size, disruption time, and cytotoxicity of pyrenefatty acid conjugates are controlled by the length of the used fatty acid. When J774.1 cells were treated with small particles of $\mathrm{P}-\mathrm{C} 12$ or $\mathrm{P}-\mathrm{C} 18$ or large particles of $\mathrm{P}-\mathrm{C} 22$, the particles were taken up by the cells according to clathrin-dependent endocytosis and/or micropinocytosis. The $\mathrm{P}-\mathrm{C} 12$ particles were smoothly disrupted and showed low cytotoxicity. On the other hand, particles of $\mathrm{P}-\mathrm{C} 18$ and $\mathrm{P}-\mathrm{C} 22$ did not exhibit any significant disruption and consequently exhibited high cytotoxicity. Thus, considering the differences in the disruption time, it is expected that the release of drugs cocrystallized with pyrenefatty acid conjugates can be controlled by manipulating the choice of fatty acids. 


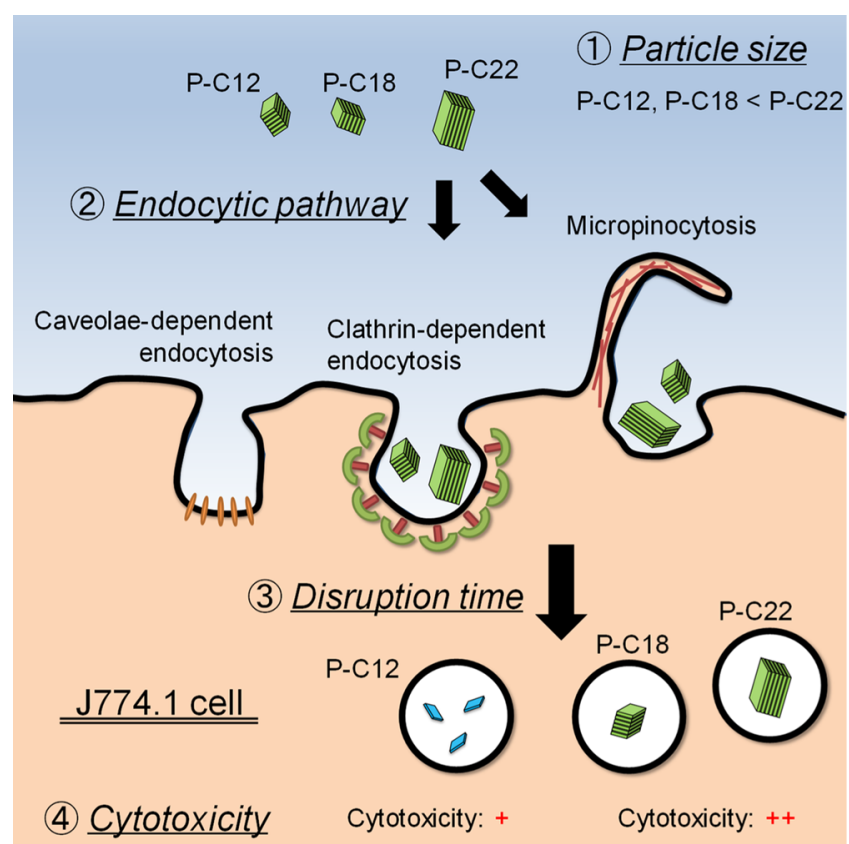

Figure 6. Schematic image of the uptake of pyrene-fatty acid conjugates by J774.1 cells.

\section{EXPERIMENTAL SECTION}

4.1. Materials. 1-Pyrenemethanol was purchased from Tokyo Chemical Industry Co. Ltd. (Tokyo, Japan). The fatty acids-(lauric acid (C12), stearic acid (C18), and behenic acid (C22)) - and 1,1'-carbonyldiimidazole (CDI) were purchased from Sigma-Aldrich (St. Louis, MO, USA). THF, chloroform, hexane, ethanol, and dimethyl sulfoxide (DMSO) were purchased from Wako Pure Chemical Industries (Osaka, Japan).

4.2. Synthesis and Crystallization of Pyrene-Fatty Acid Conjugates. Pyrene-fatty acid conjugates were synthesized using CDI as the condensation reagent (Figure S4). Equimolar amounts of the fatty acid and CDI were dissolved in THF, followed by stirring for $8 \mathrm{~h}$ at $60{ }^{\circ} \mathrm{C}$. An equimolar amount of 1-pyrenemethanol was added to this solution, which was then subjected to further stirring for $24 \mathrm{~h}$ at $60{ }^{\circ} \mathrm{C}$. The synthesized pyrene-fatty acid conjugates were purified by silica gel chromatography [ethyl acetate/hexane = 1:5, silica gel 60N (Kanto Chemical Co. Inc., Tokyo, Japan)], followed by washing with ethanol overnight. The purity of the obtained pyrene-fatty acid conjugates was evaluated by liquidstate ${ }^{1} \mathrm{H}$ nuclear magnetic resonance $\left[{ }^{1} \mathrm{H}\right.$ NMR; JNM-ECX-400 (JEOL Co. Ltd., Tokyo, Japan)] spectroscopy (Figure S5).

4.3. Crystal Growth, Analysis of the Crystal Structure, and Characterization of the Physicochemical Properties of Pyrene-Fatty Acid Conjugates. Crystals of pyrene and pyrene-fatty acid conjugates were obtained by evaporation in a chloroform solution $(50 \mathrm{mM})$. The obtained crystals were analyzed using a fluorescence microscope (IX51) with a WU filter (Ex: 330-385 nm, Em: $420 \mathrm{~nm}$ ) (Olympus, Tokyo, Japan). The crystallinities of the samples $(15 \mathrm{mg})$ were analyzed using an XRD instrument (XRD-6100, Shimadzu, Kyoto, Japan). The diffraction patterns were generated in the $2 \theta$ range of $10^{\circ}-50^{\circ}$ at a scanning rate of $4.0^{\circ} \mathrm{min}^{-1}$ using $\mathrm{Cu}$ $\mathrm{K} \alpha$ radiation at $40 \mathrm{kV}$ and $30 \mathrm{~mA}$. DSC analysis of these crystals was conducted using an X-DSC7000 differential scanning calorimeter (Hitachi High-Tech Science, Tokyo,
Japan). The samples were placed in aluminum pans and hermetically sealed; they were then cooled to $30^{\circ} \mathrm{C}$, followed by heating at $5{ }^{\circ} \mathrm{C} / \mathrm{min}$ to $200{ }^{\circ} \mathrm{C}$. The Raman spectra of pyrene and pyrene-fatty acid conjugate crystals were recorded using a confocal Raman microscope (LabRAM HR-800, Horiba Ltd., Kyoto, Japan). A YAG laser $(785 \mathrm{~nm})$ was used for excitation, and a $20 \times$ objective lens was used for the measurement.

4.4. Absorption and Fluorescence Measurements of Pyrene-Fatty Acid Conjugates. The absorption spectra of pyrene and pyrene-fatty acid conjugates solubilized in hexane $(0.01 \mathrm{mM})$ or in the solid state were measured using an ultraviolet-visible (UV-vis) spectrophotometer (UV-3600, Shimadzu, Kyoto, Japan). The fluorescence spectra of pyrene and pyrene-fatty acid conjugates solubilized in hexane ( 0.01 or $2.5 \mathrm{mM}$ ) or in the solid state were recorded using an RF5300PC fluorometer (Shimadzu, Kyoto, Japan) at an excitation wavelength of $336 \mathrm{~nm}$. During the fluorescence spectral analysis of pyrene and pyrene-fatty acid conjugates solubilized in hexane, the temperature was maintained at $60{ }^{\circ} \mathrm{C}$ to achieve complete dissolution.

4.5. Cells and Cell Culture. Murine J774.1 macrophagelike cells and murine cells derived from rectal cancer (Colon 26 cells) were provided by the RIKEN BRC through the National BioResource Project of MEXT, Japan. These cells were cultured in Eagle's minimum essential medium (E-MEM) containing $10 \%$ fetal bovine serum (FBS) in a humidified atmosphere of $5.0 \% \mathrm{CO}_{2}$ at $37^{\circ} \mathrm{C}$.

4.6. Preparation of Pyrene-Fatty Acid Conjugate Particles and Measurement of Fluorescence Spectra. The synthesized pyrene-fatty acid conjugates were suspended in EtOH because it is difficult to add pyrene-fatty acid conjugates in the solid state to cells directly. The particle preparation procedure is as follows. The conjugates $(50 \mu \mathrm{mol})$ were added to $1 \mathrm{~mL}$ of EtOH and stirred for $24 \mathrm{~h}$. Assuming complete dissolution, the final concentration of the pyrenefatty acid conjugates was $50 \mathrm{mM}$. The sizes of the conjugate particles in EtOH were measured using Zetasizer nanoZS (Malvern Instruments Ltd., Malvern, Worcestershire, UK). These suspensions were first diluted with EtOH until they could be analyzed. To generate the fluorescence spectra of the conjugate particles, $30 \mu \mathrm{L}$ of the suspended particles was added to $3 \mathrm{~mL}$ of PBS $(137 \mathrm{mM} \mathrm{NaCl}, 2.7 \mathrm{mM} \mathrm{KCl}, 10 \mathrm{mM}$ $\mathrm{Na}_{2} \mathrm{HPO}_{4}$, and $\left.2 \mathrm{mM} \mathrm{KH_{2 }} \mathrm{PO}_{4} ; \mathrm{pH} 7.3\right)$ and fluorescence spectra of these solutions were measured.

4.7. Evaluation of Particle Uptake by Cells. The uptake pathway of pyrene-fatty acid conjugate particles was analyzed as described below. Cells were seeded on 6-well culture plates $\left(2 \mathrm{~mL}, 2.0 \times 10^{5}\right.$ cells $\left./ \mathrm{mL}\right)$ and cultured for $24 \mathrm{~h}$ in E-MEM supplemented with $10 \%$ FBS in an incubator. Subsequently, the culture medium was replaced with $2 \mathrm{~mL}$ of fresh medium. The cells were then treated with endocytosis inhibitors, that is, 20 $\mu \mathrm{L}$ of $200 \mathrm{mM} \mathrm{M} \beta \mathrm{CD}$ in $\mathrm{PBS},{ }^{46} 20 \mu \mathrm{L}$ of $0.30 \mathrm{mM}$ PAO in DMSO, ${ }^{47,48} 20 \mu \mathrm{L}$ of $5.0 \mathrm{mM}$ wortmannin in DMSO, ${ }^{49,50} 1.92$ $\mu \mathrm{L}$ of $20.85 \mathrm{mM}$ cytochalasin B in DMSO, ${ }^{47} 3.84 \mu \mathrm{L}$ of 9.85 $\mathrm{mM}$ cytochalasin D in DMSO, ${ }^{47,51}$ and $20 \mu \mathrm{L}$ of $2.0 \mathrm{mM}$ EIPA in DMSO. ${ }^{52,53}$ The types of inhibitors, inhibitory pathways, and final concentrations of the inhibitors are listed in Table S1. After incubation for $2 \mathrm{~h}, 20 \mu \mathrm{L}$ of $50 \mathrm{mM}$ pyrene-fatty acid conjugate particles were added to the cells. The cells were then further incubated for $15 \mathrm{~min}$ and washed twice with PBS. They were then treated with trypsin, followed by washing twice with PBS. The fluorescence spectra of the pyrene-fatty acid 
conjugates in the cell suspension were measured using an RF5300PC fluorometer (Shimadzu; Kyoto, Japan). The conjugates in the cell suspensions were excited at $336 \mathrm{~nm}$, and spectra in the wavelength range of 350-600 $\mathrm{nm}$ were recorded. The maximum fluorescent intensities in the wavelength ranges of $350-430$ and $430-600 \mathrm{~nm}$ were considered to be the fluorescent intensities corresponding to monomer emission $\left(I_{\mathrm{M}}\right)$ and excimer emission $\left(I_{\mathrm{E}}\right)$, respectively. The uptake of $\mathrm{P}-$ $\mathrm{C} 12$ particles and particles of pyrene-fatty acid conjugates with long acyl chains $(\mathrm{P}-\mathrm{C} 18$ and $\mathrm{P}-\mathrm{C} 22)$ was evaluated in terms of $I_{\mathrm{M}}$ and $I_{\mathrm{E}}$ because only the $\mathrm{P}-\mathrm{C} 12$ particles were disrupted smoothly in the cells (see Results and Discussion). The uptake quantity was evaluated by comparing the cells treated with pyrene-fatty acid conjugate particles with intact cells.

4.8. Monitoring of the Disruption of Particles by Fluorescence Spectral Analysis. The time to disruption of the pyrene-fatty acid conjugate particles was measured using a method similar to the one described in the previous section. Cells were seeded on 6-well culture plates $\left(2 \mathrm{~mL}, 2.0 \times 10^{5}\right.$ cells $/ \mathrm{mL}$ ) and cultured for $24 \mathrm{~h}$ in E-MEM supplemented with $10 \%$ FBS in an incubator. The culture medium was then replaced with $2 \mathrm{~mL}$ of fresh medium containing $20 \mu \mathrm{L}$ of 50 $\mathrm{mM}$ of pyrene-fatty acid conjugate particles suspended in EtOH. The cells were incubated for $15 \mathrm{~min}$, and the culture medium was then replaced with $2 \mathrm{~mL}$ of fresh medium to evaluate the disruption of initially taken pyrene-fatty acid conjugate particles. At the end of the incubation time, the cells were treated with trypsin and washed twice with PBS. The fluorescence spectra of the pyrene-fatty acid conjugates in cell suspensions were measured using an RF-5300PC fluorometer. The time to disruption was evaluated based on the ratio of $I_{\mathrm{M}}$ and $I_{\mathrm{E}}$.

4.9. Evaluation of Cytotoxicity by 3-(4,5-Dimethylthiazol-2-yl)-2,5-diphenyltetrazolium Bromide Assay. 3(4,5-Dimethylthiazol-2-yl)-2,5-diphenyltetrazolium bromide (MTT) assay was performed using a CellTiter 96 NonRadioactive Cell Proliferation Assay kit (Promega, Fitchburg, WI, USA). Cells were seeded on 96-well culture plates $(100 \mu \mathrm{L}$, $2.0 \times 10^{5}$ cells $/ \mathrm{mL}$ ) and cultured for $24 \mathrm{~h}$ in E-MEM supplemented with $10 \%$ FBS in the incubator. The culture medium was later replaced with $100 \mu \mathrm{L}$ of fresh medium. Subsequently, $1 \mu \mathrm{L}$ of $\sim 100 \mathrm{mM}$ pyrene-fatty acid conjugate (final concentration: $5.0 \times 10^{-4}$ to $1 \mathrm{mM}$ ) was added to the cells; the cells were then incubated for $24 \mathrm{~h}\left(37^{\circ} \mathrm{C}, 5 \% \mathrm{CO}_{2}\right)$. A dye solution $(15 \mu \mathrm{L})$ was added to the medium. After incubation for $4 \mathrm{~h}, 100 \mu \mathrm{L}$ of solubilization solution/stop mix was added to the medium. After incubation for $1 \mathrm{~h}$ at $25^{\circ} \mathrm{C}$, the absorbance of each well was measured using a microplate spectrophotometer, iMark (Bio-Rad, Hercules, CA, USA). The ratio of cell viability was calculated using the following equation

$$
\text { Ratio of cell viability }=\left(A_{570}-A_{630}\right) /\left(A_{570(0)}-A_{630(0)}\right)
$$

where $A_{570}$ and $A_{630}$ are the absorbance values at 570 and 630 $\mathrm{nm}$, respectively, when cells were treated with pyrene-fatty acid conjugate particles. $A_{570(0)}$ and $A_{630(0)}$ refer to the absorbance values at 570 and $630 \mathrm{~nm}$, respectively, when cells were treated with PBS. The absorbance at $570 \mathrm{~nm}$ was measured to determine the quantity of formazan dye. The absorbance at $630 \mathrm{~nm}$ was measured to reduce the effect of cell debris.

\section{ASSOCIATED CONTENT}

\section{Supporting Information}

The Supporting Information is available free of charge on the ACS Publications website at DOI: 10.1021/acsomega.7b02061.

Types of endocytosis inhibitors, inhibitory pathways, and final concentrations of the inhibitors; DSC analysis of the fatty acids-lauric acid (C12), stearic acid (C18), and behenic acid (C22). Glass transition (arrows) was observed in addition to a definite peak corresponding to the melting point in all thermograms; fluorescence spectra of highly concentrated pyrene-modified fatty acids and pyrene $(2.5 \mathrm{mM})$. Excimer emission was observed at $2.5 \mathrm{mM}$; particle size distribution of (a) $\mathrm{P}-$ C12, (b) P-C18, and (c) P-C22. Particle diameter was measured three times; scheme of the synthesis of pyrene-fatty acid conjugates. 1-Pyrenemethanol was conjugated with fatty acids [lauric acid (C12), stearic acid (C18), and behenic acid (C22)] using a condensation reagent, $\mathrm{CDI}$, in THF; and ${ }^{1} \mathrm{H}$ NMR spectra of pyrene-fatty acid conjugates, $\mathrm{P}-\mathrm{C} 12, \mathrm{P}-\mathrm{C} 18$, and $\mathrm{P}-\mathrm{C} 22$. All spectra were similar. The intensity of the peak assigned to $\left(\mathrm{CH}_{2}\right)_{n}$ increased upon changing the conjugated fatty acid from lauric acid $(\mathrm{C} 12)$ to stearic acid (C18) and behenic acid (C22) (PDF)

\section{AUTHOR INFORMATION}

\section{Corresponding Authors}

*E-mail: hayashi@chem.nara-k.ac.jp. Phone: +81 0743556152. Fax: +81 0743-55-6169 (K.H.).

*E-mail: umakoshi@chem.es.osaka-u.ac.jp. Phone: +81066850 6287. Fax: +810668506286.

ORCID

Keita Hayashi: 0000-0002-3119-9732

Toshiyuki Kamei: 0000-0001-8435-3767

Keishi Suga: 0000-0001-8015-8729

Hiroshi Umakoshi: 0000-0002-9241-853X

Notes

The authors declare no competing financial interest.

\section{ACKNOWLEDGMENTS}

This work was supported by Grant-in-Aids for Scientific Research (A) (26249116) and Young Scientists (B) (15K18279) from the Japan Society for the Promotion of Science (JSPS). Murine J774.1 macrophage-like cells and murine cells derived from rectal cancer (Colon 26 cells) were provided by the RIKEN BRC through the National BioResource Project of the MEXT, Japan.

\section{REFERENCES}

(1) Gao, F.; Liao, Q.; Xu, Z.-Z.; Yue, Y.-H.; Wang, Q.; Zhang, H.-L.; Fu, H.-B. Strong two-photon excited fluorescence and stimulated emission from an organic single crystal of an oligo(phenylene vinylene). Angew. Chem., Int. Ed. 2010, 49, 732-735.

(2) Gymer, R. W. Organic electroluminescent displays. Endeavour 1996, 20, 115-120.

(3) Giuliano, K. A.; Taylor, D. L. Fluorescent-protein biosensors: new tools for drug discovery. Trends Biotechnol. 1998, 16, 135-140.

(4) Newman, R. H.; Fosbrink, M. D.; Zhang, J. Genetically encodable fluorescent biosensors for tracking signaling dynamics in living cells. Chem. Rev. 2011, 111, 3614-3666. 
(5) Süel, G. Use of fluorescence microscopy to analyze genetic circuit dynamics. In Methods in Enzymology; Voigt, C., Ed.; Academic Press, 2011; Chapter 13, Vol. 497, pp 275-293.

(6) Rajagopal, S. K.; Philip, A. M.; Nagarajan, K.; Hariharan, M. Progressive acylation of pyrene engineers solid state packing and colour via $\mathrm{C}-\mathrm{H} \cdots \mathrm{H}-\mathrm{C}, \mathrm{C}-\mathrm{H} \cdots \mathrm{O}$ and $\pi-\pi$ interactions. Chem. Commun. 2014, 50, 8644-8647.

(7) Hinoue, T.; Shigenoi, Y.; Sugino, M.; Mizobe, Y.; Hisaki, I.; Miyata, M.; Tohnai, N. Regulation of $\pi$-stacked anthracene arrangement for fluorescence modulation of organic solid from monomer to excited oligomer emission. Chem.-Eur. J. 2012, 18, 4634-4643.

(8) Kubin, R. F.; Fletcher, A. N. Fluorescence quantum yields of some rhodamine dyes. J. Lumin. 1982, 27, 455-462.

(9) Sjöback, R.; Nygren, J.; Kubista, M. Absorption and fluorescence properties of fluorescein. Spectrochim. Acta, Part A 1995, 51, L7-L21.

(10) Toseland, C. P. Fluorescent labeling and modification of proteins. J. Chem. Biol. 2013, 6, 85-95.

(11) Kirkham, S.; Hamley, I. W.; Smith, A. M.; Gouveia, R. M.; Connon, C. J.; Reza, M.; Ruokolainen, J. A self-assembling fluorescent dipeptide conjugate for cell labelling. Colloids Surf., B 2016, 137, 104108.

(12) Fleming, S.; Ulijn, R. V. Design of nanostructures based on aromatic peptide amphiphiles. Chem. Soc. Rev. 2014, 43, 8150-8177.

(13) Ardoña, H. A. M.; Tovar, J. D. Peptide $\pi$-electron conjugates: organic electronics for biology? Bioconjugate Chem. 2015, 26, 22902302.

(14) Freeman, R.; Li, Y.; Tel-Vered, R.; Sharon, E.; Elbaz, J.; Willner, I. Self-assembly of supramolecular aptamer structures for optical or electrochemical sensing. Analyst 2009, 134, 653-656.

(15) Yang, C. J.; Jockusch, S.; Vicens, M.; Turro, N. J.; Tan, W. Lightswitching excimer probes for rapid protein monitoring in complex biological fluids. Proc. Natl. Acad. Sci. U.S.A. 2005, 102, 17278-17283.

(16) Korte, W. D. 9(chloromethyl)anthracene: a useful derivatizing reagent for enhanced ultraviolet and fluorescence detection of carboxylic acids with liquid chromatography. J. Chromatogr. A 1982, 243, 153-157.

(17) Duenges, W. 4-Bromomethyl-7-methoxycoumarin as a new fluorescence label for fatty acids. Anal. Chem. 1977, 49, 442-445.

(18) Chayen, R.; Dvir, R.; Gould, S.; Harell, A. 1-Dimethylaminonaphthalene-5-sulfonyl hydrazine (dansyl hydrazine): a fluorometric reagent for carbonyl compounds. Anal. Biochem. 1971, 42, 283-286.

(19) Suleimanov, I.; Kraieva, O.; Costa, J. S.; Fritsky, I. O.; Molnár, G.; Salmon, L.; Bousseksou, A. Electronic communication between fluorescent pyrene excimers and spin crossover complexes in nanocomposite particles. J. Mater. Chem. C 2015, 3, 5026-5032.

(20) Soutar, A. K.; Pownall, H. J.; Hu, A. S.; Smith, L. C. Phase transitions in bilamellar vesicles. Measurements by pyrene excimer fluorescence and effect on transacylation by lecithin-cholesterol acyltransferase. Biochemistry 1974, 13, 2828-2836.

(21) Katoh, R.; Suzuki, K.; Furube, A.; Kotani, M.; Tokumaru, K. Fluorescence quantum yield of aromatic hydrocarbon crystals. J. Phys. Chem. C 2009, 113, 2961-2965.

(22) Warshel, A.; Huler, E. Theoretical evaluation of potential surfaces, equilibrium geometries and vibronic transition intensities of excimers: the pyrene crystal excimer. Chem. Phys. 1974, 6, 463-468.

(23) Langenegger, S. M.; Häner, R. Excimer formation by interstrand stacked pyrenes. Chem. Commun. 2004, 2792-2793.

(24) Moriuchi, T.; Tamura, T.; Hirao, T. Self-Assembly of dipeptidyl ureas: a new class of hydrogen-bonded molecular duplexes. J. Am. Chem. Soc. 2002, 124, 9356-9357.

(25) Turro, N. J.; Kuo, P. L. Excimer formation of a water-soluble fluorescence probe in anionic micelles and nonionic polymer aggregates. Langmuir 1987, 3, 773-777.

(26) Turro, N. J.; Kuo, P. L. Pyrene excimer formations in micelles of nonionic detergents and of water-soluble polymers. Langmuir 1986, 2, 438-442.

(27) Ilharco, L. M.; Santos, A. M.; Silva, M. J.; Martinho, J. M. G. Intramolecular pyrene excimer probing the sol-gel process. Langmuir 1995, 11, 2419-2422.
(28) Roy, B. C.; Chandra, B.; Hromas, D.; Mallik, S. Synthesis of new, pyrene-containing, metal-chelating lipids and sensing of cupric ions. Org. Lett. 2003, 5, 11-14.

(29) Gai, L.; Chen, H.; Zou, B.; Lu, H.; Lai, G.; Li, Z.; Shen, Z. Ratiometric fluorescence chemodosimeters for fluoride anion based on pyrene excimer/monomer transformation. Chem. Commun. 2012, 48, 10721-10723.

(30) Lasic, D. D. Doxorubicin in sterically stabilized liposomes. Nature 1996, 380, 561-562.

(31) Rivera, E. Liposomal anthracyclines in metastatic breast cancer: clinical update. Oncologist 2003, 8, 3-9.

(32) Murphy, M. P.; Smith, R. A. J. Drug delivery to mitochondria: the key to mitochondrial medicine. Adv. Drug Delivery Rev. 2000, 41, 235-250.

(33) Rewatkar, P. V.; Parton, R. G.; Parekh, H. S.; Parat, M.-O. Are caveolae a cellular entry route for non-viral therapeutic delivery systems? Adv. Drug Delivery Rev. 2015, 91, 92-108.

(34) Rehman, Z. u.; Zuhorn, I. S.; Hoekstra, D. How cationic lipids transfer nucleic acids into cells and across cellular membranes: recent advances. J. Controlled Release 2013, 166, 46-56.

(35) Hayashi, K.; Iwai, H.; Kamei, T.; Iwamoto, K.; Shimanouchi, T.; Fujita, S.; Nakamura, H.; Umakoshi, H. Tailor-made drug carrier: comparison of formation-dependent physicochemical properties within self-assembled aggregates for an optimal drug carrier. Colloids Surf., B 2017, 152, 269-276.

(36) Hu, Q.; Rijcken, C. J. F.; van Gaal, E.; Brundel, P.; Kostkova, H.; Etrych, T.; Weber, B.; Barz, M.; Kiessling, F.; Prakash, J.; Storm, G.; Hennink, W. E.; Lammers, T. Tailoring the physicochemical properties of core-crosslinked polymeric micelles for pharmaceutical applications. J. Controlled Release 2016, 244, 314-325.

(37) Krämer, S. D.; Aschmann, H. E.; Hatibovic, M.; Hermann, K. F.; Neuhaus, C. S.; Brunner, C.; Belli, S. When barriers ignore the "ruleof-five”. Adv. Drug Delivery Rev. 2016, 101, 62-74.

(38) Costa, A.; Pinheiro, M.; Magalhães, J.; Ribeiro, R.; Seabra, V.; Reis, S.; Sarmento, B. The formulation of nanomedicines for treating tuberculosis. Adv. Drug Delivery Rev. 2016, 102, 102-115.

(39) Cedeño, F. O.; Prieto, M. M.; Espina, A.; García, J. R. Measurements of temperature and melting heat of some pure fatty acids and their binary and ternary mixtures by differential scanning calorimetry. Thermochim. Acta 2001, 369, 39-50.

(40) Jones, C. L.; Bantz, K. C.; Haynes, C. L. Partition layer-modified substrates for reversible surface-enhanced Raman scattering detection of polycyclic aromatic hydrocarbons. Anal. Bioanal. Chem. 2009, 394, 303-311.

(41) Colangeli, L.; Mennella, V.; Baratta, G. A.; Bussoletti, E.; Strazzulla, G. Raman and infrared spectra of polycyclic aromatic hydrocarbon molecules of possible astrophysical interest. Astrophys. J. 1992, 396, 369-377.

(42) Salini, P. S.; Rajagopal, S. K.; Hariharan, M. Haloacetylationdriven transformation of sandwich herringbone to lamellar/columnar packing in pyrene. Cryst. Growth Des. 2016, 16, 5822-5830.

(43) Goldschmidt, C. R.; Ottolenghi, M. Absorption spectrum of the pyrene excimer. J. Phys. Chem. 1970, 74, 2041-2042.

(44) Ernsting, M. J.; Murakami, M.; Roy, A.; Li, S.-D. Factors controlling the pharmacokinetics, biodistribution and intratumoral penetration of nanoparticles. J. Controlled Release 2013, 172, 782-794.

(45) Sahay, G.; Alakhova, D. Y.; Kabanov, A. V. Endocytosis of nanomedicines. J. Controlled Release 2010, 145, 182-195.

(46) MacDougall, D. A.; Agarwal, S. R.; Stopford, E. A.; Chu, H.; Collins, J. A.; Longster, A. L.; Colyer, J.; Harvey, R. D.; Calaghan, S. Caveolae compartmentalise $\beta 2$-adrenoceptor signals by curtailing cAMP production and maintaining phosphatase activity in the sarcoplasmic reticulum of the adult ventricular myocyte. J. Mol. Cell. Cardiol. 2012, 52, 388-400.

(47) Linares, J.; Matesanz, M. C.; Vila, M.; Feito, M. J.; Gonçalves, G.; Vallet-Regí, M.; Marques, P. A. A. P.; Portolés, M. T. Endocytic mechanisms of graphene oxide nanosheets in osteoblasts, hepatocytes and macrophages. ACS Appl. Mater. Interfaces 2014, 6, 13697-13706. 
(48) Bale, S. S.; Kwon, S. J.; Shah, D. A.; Banerjee, A.; Dordick, J. S.; Kane, R. S. Nanoparticle-mediated cytoplasmic delivery of proteins to target cellular machinery. ACS Nano 2010, 4, 1493-1500.

(49) Li, G.; D’Souza-Schorey, C.; Barbieri, M. A.; Roberts, R. L.; Klippel, A.; Williams, L. T.; Stahl, P. D. Evidence for phosphatidylinositol 3-kinase as a regulator of endocytosis via activation of Rab5. Proc. Natl. Acad. Sci. U.S.A. 1995, 92, 10207-10211.

(50) Patki, V.; Virbasius, J.; Lane, W. S.; Toh, B.-H.; Shpetner, H. S.; Corvera, $\mathrm{S}$. Identification of an early endosomal protein regulated by phosphatidylinositol3-kinase. Proc. Natl. Acad. Sci. U.S.A. 1997, 94, 7326-7330.

(51) Wang, H.; Wu, L.; Reinhard, B. M. Scavenger receptor mediated endocytosis of silver nanoparticles into J774A.1 macrophages is heterogeneous. ACS Nano 2012, 6, 7122-7132.

(52) Banga, H. S.; Simons, E. R.; Brass, L. F.; Rittenhouse, S. E. Activation of phospholipases $\mathrm{A}$ and $\mathrm{C}$ in human platelets exposed to epinephrine: role of glycoproteins IIb/IIIa and dual role of epinephrine. Proc. Natl. Acad. Sci. U.S.A. 1986, 83, 9197-9201.

(53) Chen, C.-J.; Wang, J.-C.; Zhao, E.-Y.; Gao, L.-Y.; Feng, Q.; Liu, X.-Y.; Zhao, Z.-X.; Ma, X.-F.; Hou, W.-J.; Zhang, L.-R.; Lu, W.-L.; Zhang, Q. Self-assembly cationic nanoparticles based on cholesterolgrafted bioreducible poly(amidoamine) for siRNA delivery. Biomaterials 2013, 34, 5303-5316. 